\title{
Search Engines and Related Open Tools for Establishing a Term Base
}

Cristian Lakó

Petru Maior University, Tg. Mureș, Romania

\section{Introduction}

In this paper we speak of openness in translation in the context of collecting and curating a terminology database for the purpose of translating on-line content in the case of multilingual websites. Whereas openness in translation is often considered from the perspective of the (on-line) tools employed (free vs. paid) or from the point of view of the translatum producers (community enthusiasts vs. professionals), we suggest using open and on-line tools for determining a term base, as a pre-editing translation process. A term base is required for consistency all over the translated content of a website and based on user input in search engines. Search engines such as Google, Bing, and Yahoo collect user input and make it available for on-line marketing purposes as keywords. Such keywords, in this case considered as central words in a text, can be regarded as translation suggestions to be used in a target text (TT). Translation based on this approach is often referred to as SEO (Search engine optimization) translation and SEO localization and make the process of opting for "the right translation" be grounded on statistical data; therefore translation is no longer a decision-making process. A similar concept to SEO translation is international SEO.

Also, as a pre-editing translation method, this approach corroborates Nord's instrumental translation (2005), and Eugene Nida's receptor-oriented theory (Dimitriu 2009: 26) by accurately establishing a common linguistic context between the text producer and the potential target readers. The usage of keywords determines the context of the TT, further emphasizing that translation can function as "an independent message transmitting instrument in a new communicative action in the target culture" (Nord 2005: 81). From a strictly linguistic point of view, Nord's definition of instrumental translation, can be also referred to as part of the localization process as we will see later on. From the perspective of localization, researched keywords can represent the local mix or locale (seen in this case as a group of users with similar interests) and they can also be used to profile the potential search engine users. By choosing the appropriate keywords (see long-tail keywords below) most search engine users can become receivers and not just addressees (see Nord's distinction - 1997: 22). 
Using keywords as the starting point in the translation process is justified when considering that the most efficient way of on-line marketing is through web pages (see Figure 1). The main component of web pages is content, especially searchable textual content indexed by search engines. This is a solid argument to build a term base founded on keyword research.

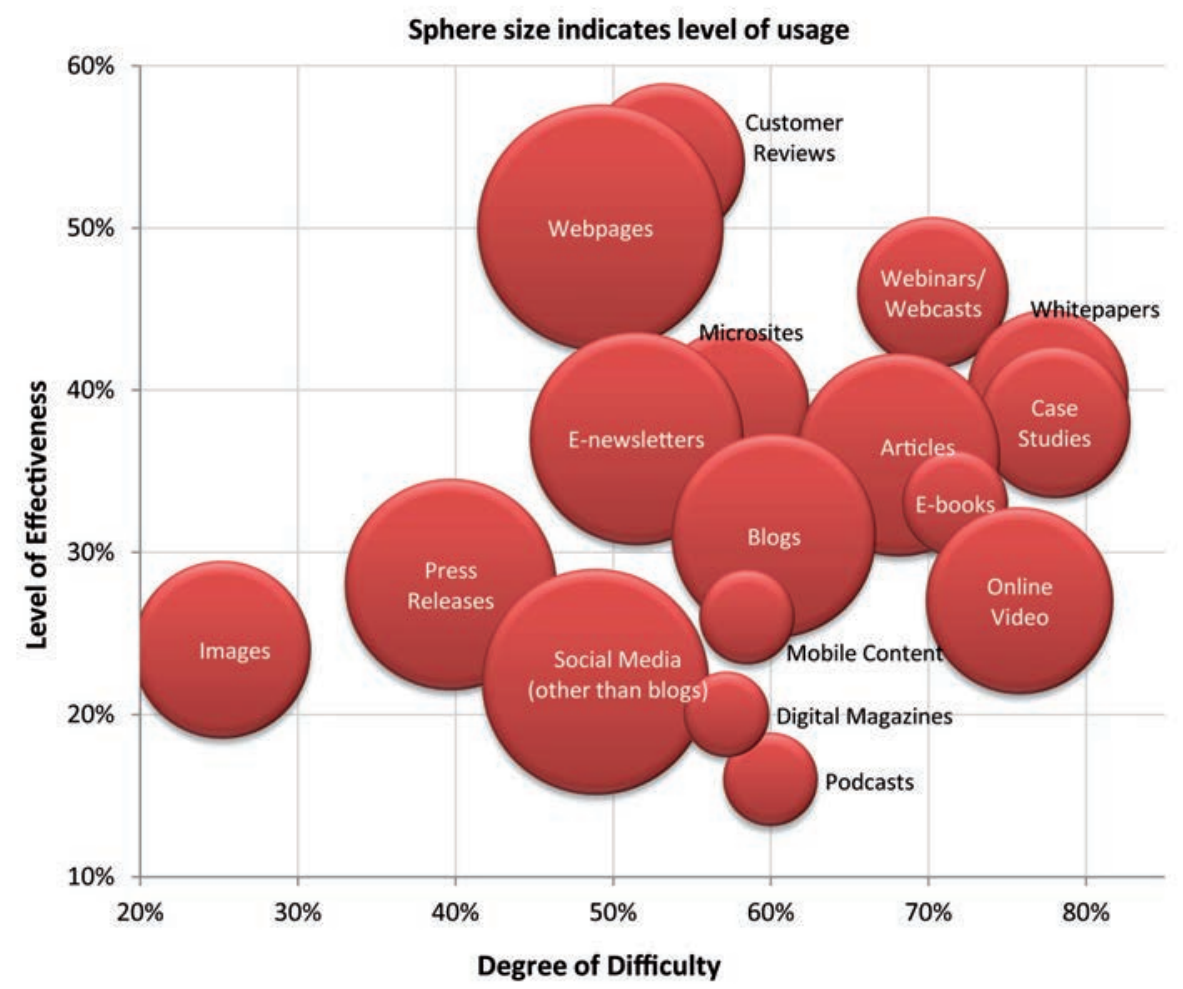

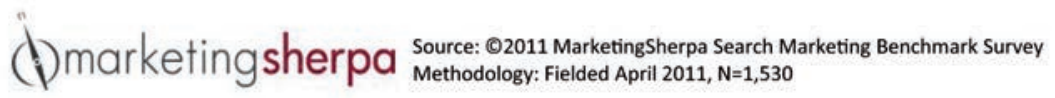

Figure 1: Effectiveness vs. degree of difficulty of various on-line marketing channels [1].

\section{Methodology}

Keyword research for SEO purposes can be conducted by means of readily available on-line tools such as Google AdWords Keyword Planner [2], Bing 
Keyword Research [3], ubersuggest.org, Google Trends [4], and even suggestions on the SERPs (search engine results page). These tools provide statistical information on user input (keywords) in search engine, thus, determining the most appropriate translation focused on end-users. Choosing this type of methodology, namely using on-line marketing strategies, applied to the translation process is based on the findings of several research groups that determined that the most efficient way of on-line marketing is through website content marketing (See Figure 1).

By employing such tools, translation appropriateness is determined by user usage (vox populi) and not by prescriptive language rules (linguistic correctness; consider misspellings, inappropriate word usage, faulty syntax, etc.) as trained in university translation courses.

Search engines reflect how vocabulary preferences shift from one period to another. Therefore, for optimal communication through the translated text, it is important to mirror the linguistic preferences of the target readers of the TT. In terms of the translation process, this step is a pre-editing process. Correctly determining during this phase the correct word base is important for the general workflow of the translation process. For instance, for the English term website(s), in Romanian site, website, sait in the singular and siteuri and saituri are used for the plural forms, maintaining the pronunciation of the English term, whereas sit web and its plural situri web are very rarely used. By comparing the definition for the English term site [5] and the Romanian sit [6] linguists would have probably opted for sit, as used within the collocation sit arheologic (archeological site). Google Translate, probably based on statistical data, suggests website and site, whereas Bing Translator translates it as site-ul, adding the Romanian definite article -ul. In a previous study (Lakó 2009: 762-763) we showed that the preferred search term for the English free games was jocuri free. This preference faded away to the benefit of a full translation: jocuri gratis and jocuri gratuite. (Google Trends set to Romania and Romanian is useful to track user preference over time diachronic view).

For the purpose of this paper we consider how reverse localization (Schäler 2002) can be fruitfully achieved by using the free tools mentioned above to determine the most efficient term base. On-line marketing through content marketing is based on the fact that content from web pages can be easier accessed by employing in TT words and expressions used by search engine users. Reverse localization refers to a process that is directed from a marginal language or culture (Romanian or Hungarian, etc.) to a major language/culture (English or German, etc.) We are particularly interested in Romanian to English translation and localization pre-editing processes. 


\section{Case Study}

With the acceptance of Romania in the EU, new opportunities emerged for Romanian products and services. As a case study for this paper, we opted for "dental tourism", a booming industry in the Eastern European countries. Focus is on Romanian dental service providers that advertise themselves on the UK market, such as dental-art.ro, dentartbucharest.com, dentesse.ro with its UK URL: http://www.affordabledentistry.ca.uk, etc. However, analyzing the texts on these websites is not part of this study.

A prerequisite for a successful analysis is to set the tools to reflect information from the target market, in this case the UK market.

\subsection{Open Tools for Keyword Analysis:}

\subsubsection{Google Adwords Keyword Planner}

Google AdWords Keyword Planner (set to UK and English) is the tool to start with as it offers a reliable insight into what terms and expressions are related to the concept of dental tourism. This application provides a wide range of options to build a list of words and expressions based on a particular topic. However, using the default settings can most often offer a good insight into the keywords most frequently entered into search engines by users who are interested in such services. By default, this tool lists group ideas. The top entries are grouped under various headings and the full list contained over 800 suggestions (viewed on the $20^{\text {th }}$ of August 2015).

\section{Table 1: Partial list of suggested keywords}

\begin{tabular}{|l|}
\hline Dental Implants (27) \\
\hline dental implants, dental implant, implants dental, how much are dental implants, dental \\
implant procedure, dental implants uk, dental implants procedure, dental implants \\
problems, mini dental implants, implant dental, best dental implants, all on 4 dental \\
implants, cheapest dental implants, dental implants budapest, dental implant surgery, \\
same day dental implants, all on four dental implants, budapest dental implants, types of \\
dental implants, dental implant specialist...
\end{tabular}




\begin{tabular}{|c|}
\hline Dentistry (55) \\
\hline $\begin{array}{l}\text { cosmetic dentistry, dentistry, cosmetic dentistry prices, sedation dentistry, cosmetic } \\
\text { dentistry cost, restorative dentistry, dentistry abroad, cosmetic dentistry abroad, implant } \\
\text { dentistry, dentistry for you, free dentistry, laser dentistry, family dentistry, dentistry in } \\
\text { hungary, holistic dentistry, pain free dentistry, dentistry for all, affordable cosmetic } \\
\text { dentistry, dentistry today, general dentistry... }\end{array}$ \\
\hline Teeth Whitening (6) \\
\hline $\begin{array}{l}\text { laser teeth whitening, teeth whitening, professional teeth whitening, zoom teeth } \\
\text { whitening, teeth whitening dentist, cheap teeth whitening }\end{array}$ \\
\hline Dentures (15) \\
\hline $\begin{array}{l}\text { dentures, partial dentures, dentures cost, denture, permanent dentures, denture } \\
\text { implants, cost of dentures, dentures prices, cheap dentures, implant retained dentures, } \\
\text { dentures in a day, affordable dentures, denture cost, cosmetic dentures cost, smile } \\
\text { dentures }\end{array}$ \\
\hline Dentist Prices (6) \\
\hline $\begin{array}{l}\text { dentist prices, private dentist prices, dentist price list, dentist price, dentists prices, } \\
\text { dentist treatment prices }\end{array}$ \\
\hline Cost Of Dental (24) \\
\hline $\begin{array}{l}\text { dental costs, dental bridge cost, dental crown cost, dental treatment costs, cost of dental } \\
\text { treatment, dental cost, dental crowns cost, dental veneers cost, dental cleaning cost, } \\
\text { dental treatment cost, cost of dental crown, dental care costs, dental surgery cost, cost } \\
\text { of dental care, average dental costs, dental implant cost, cost of dental, lost cost dental } \\
\text { care, cost dental, dental care cost... }\end{array}$ \\
\hline Teeth Implants (6) \\
\hline $\begin{array}{l}\text { teeth implants, implants teeth, implant teeth, teeth implant, implants for teeth, implants in } \\
\text { teeth }\end{array}$ \\
\hline Tooth (18) \\
\hline $\begin{array}{l}\text { tooth implants, tooth implant, tooth crown, tooth whitening, tooth bonding, tooth } \\
\text { replacement cost, tooth bridge, tooth extraction, tooth extraction cost, tooth crown cost, } \\
\text { tooth filling, implant tooth, tooth crowns, tooth implant procedure, tooth replacement } \\
\text { options, tooth filling cost, tooth bonding cost, implants tooth }\end{array}$ \\
\hline Dental Abroad (10) \\
\hline $\begin{array}{l}\text { dental implants abroad, dental treatment abroad, dental work abroad, dental abroad, } \\
\text { cheap dental treatment abroad, dental care abroad, cheap dental implants abroad, cost } \\
\text { of dental implants abroad, dental implant abroad, dental procedures abroad }\end{array}$ \\
\hline Teeth (39) \\
\hline $\begin{array}{l}\text { teeth whitening prices, teeth whitening cost, teeth implants cost, teeth bleaching, false } \\
\text { teeth, teeth cleaning, teeth replacement, crowns for teeth, teeth problems, teeth crowns, } \\
\text { crown teeth, teeth caps, teeth bonding, teeth cleaning cost, teeth treatment, cost of teeth } \\
\text { implants, teeth inplants, teeth implants prices, crowns on teeth, teeth dentist... }\end{array}$ \\
\hline
\end{tabular}




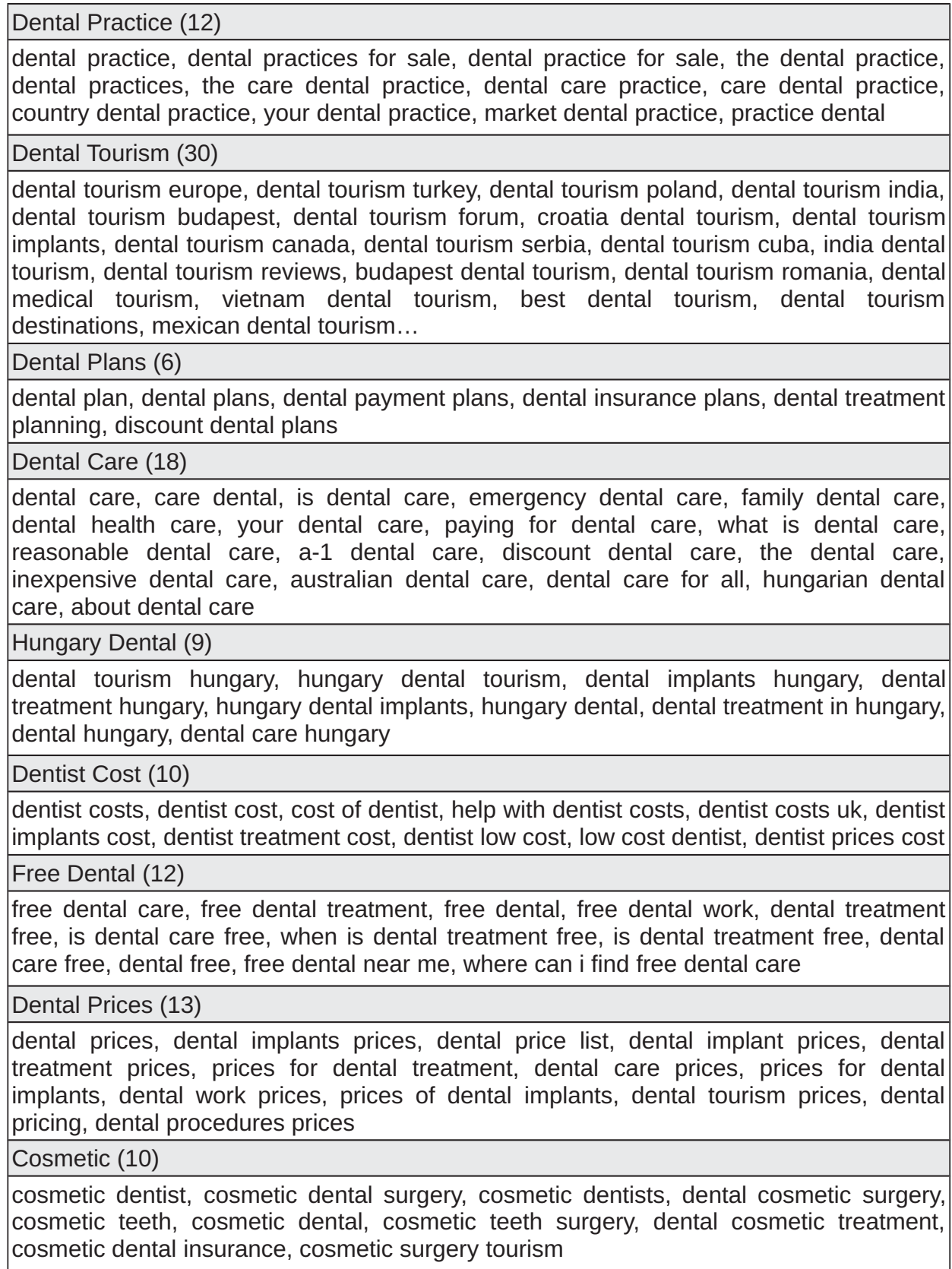




\begin{tabular}{|c|}
\hline Cheap Dental (13) \\
\hline $\begin{array}{l}\text { cheap dental implants, cheap dental treatment, cheap dental implant, cheap dental work, } \\
\text { cheap dental insurance, cheap dental crowns, cheap dental care, cheap dental, cheap } \\
\text { dental surgery, cheap dental plans, dental cheap, cheap dental clinics, cheap dental } \\
\text { service }\end{array}$ \\
\hline Dental Treatment (5) \\
\hline $\begin{array}{l}\text { dental treatment, dental treatments, private dental treatment, complex dental treatment, } \\
\text { dental care treatment }\end{array}$ \\
\hline Dental Insurance (12) \\
\hline $\begin{array}{l}\text { private dental insurance, compare dental insurance, dental health insurance, full } \\
\text { coverage dental insurance, cheapest dental insurance, full dental insurance, how much } \\
\text { is dental insurance, is dental insurance worth it, buy dental insurance, no dental } \\
\text { insurance need dentist, no dental insurance, aflac dental insurance }\end{array}$ \\
\hline Free Dentist (5) \\
\hline free dentist, free dentist treatment, is the dentist free, free dentist care, dentist for free \\
\hline Dental Clinic (8) \\
\hline $\begin{array}{l}\text { dental clinic, dental implant clinic, the dental clinic, dental clinics, walk in dental clinic, } \\
\text { dental implant clinics, dental implants clinics, dental implants clinic }\end{array}$ \\
\hline Dental Help (10) \\
\hline $\begin{array}{l}\text { help with dental costs, dental help, help with dental care, dental cost help, help with } \\
\text { dental treatment, help with dental cost, help with dental care costs, free dental help, help } \\
\text { for dental care, dental care help }\end{array}$ \\
\hline Medical Tourism (27) \\
\hline $\begin{array}{l}\text { medical tourism, medical tourism uk, medical tourism thailand, thailand medical tourism, } \\
\text { what is medical tourism, medical tourism companies, medical tourism in thailand, } \\
\text { medical tourism statistics, medical tourism europe, medical tourism india, medical } \\
\text { tourism definition, uk medical tourism, medical tourism poland, medical tourism agency, } \\
\text { medical tourism destinations, india medical tourism, medical tourism providers, medical } \\
\text { tourism dentistry, medical tourism costa rica, costa rica medical tourism... }\end{array}$ \\
\hline Abroad (6) \\
\hline $\begin{array}{l}\text { dentist abroad, treatment abroad, dentists abroad, medical treatment abroad, medical } \\
\text { holidays abroad, tourism abroad }\end{array}$ \\
\hline Costa Rica (19) \\
\hline $\begin{array}{l}\text { costa rica tourism, visit costa rica, costa rica travel, costa rica adventure, travel costa } \\
\text { rica, costa rica destinations, travel to costa rica, costa rica tourist attractions, costa rica } \\
\text { where to go, costa rica packages, costa rica deals, tourism costa rica, costa rica trip, } \\
\text { where to go costa rica, costa rica adventures, why go to costa rica, traveling to costa } \\
\text { rica, implants costa rica, costa rica implants }\end{array}$ \\
\hline
\end{tabular}

A gist of the list shows that curating is needed. There are at least two obvious criteria to consider: relevance, on the one hand, and linguistic and 
marketing effectiveness on the other. From the perspective of relevance, considering that companies under discussion are Romanian companies, keywords that contain terms such as Budapest, Hungary, Poland, Thailand, India, Costa Rica, near me and other non-Romanian geographical areas are not relevant. Also, keywords such as what is medical tourism, medical tourism definition, medical tourism statistics are clearly relevant for information only searches. All one-word keywords were also removed. This generated a list of 494 two-, three-, four-, five- and six-word keywords.

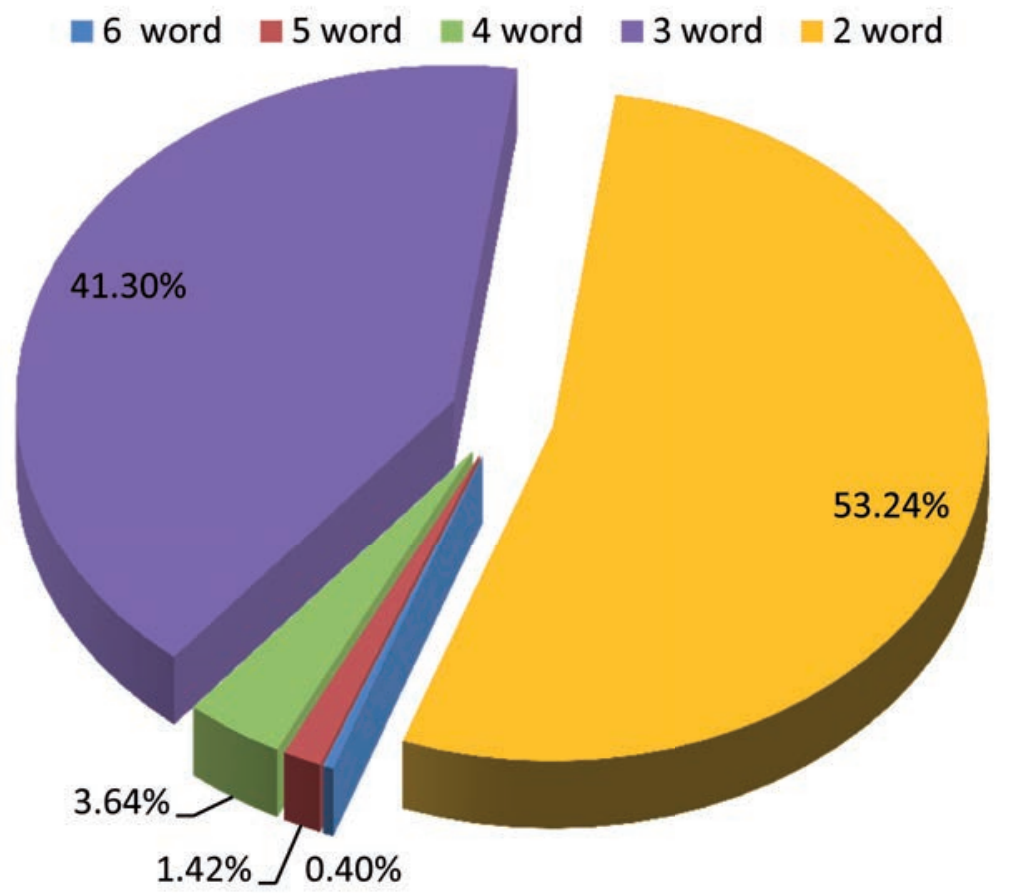

Figure 2: Percentages of keyword length suggested by Keyword

Planner after initial curating from six-word to two-word keywords.

As for language usage and marketing effectiveness, several online marketing studies [7][8][9] show that long-tail keywords are more result oriented. One-, two- and three-word long keywords are not as efficient and often reflect the users' non-commitment phase. This means that users are looking for information and are only in the early stages of the buying cycle. The diagram below summarizes the views of SEO companies on the 
efficiency of long-tail keywords. The longer the keyword, the higher the probability of converting a visitor into a buyer.

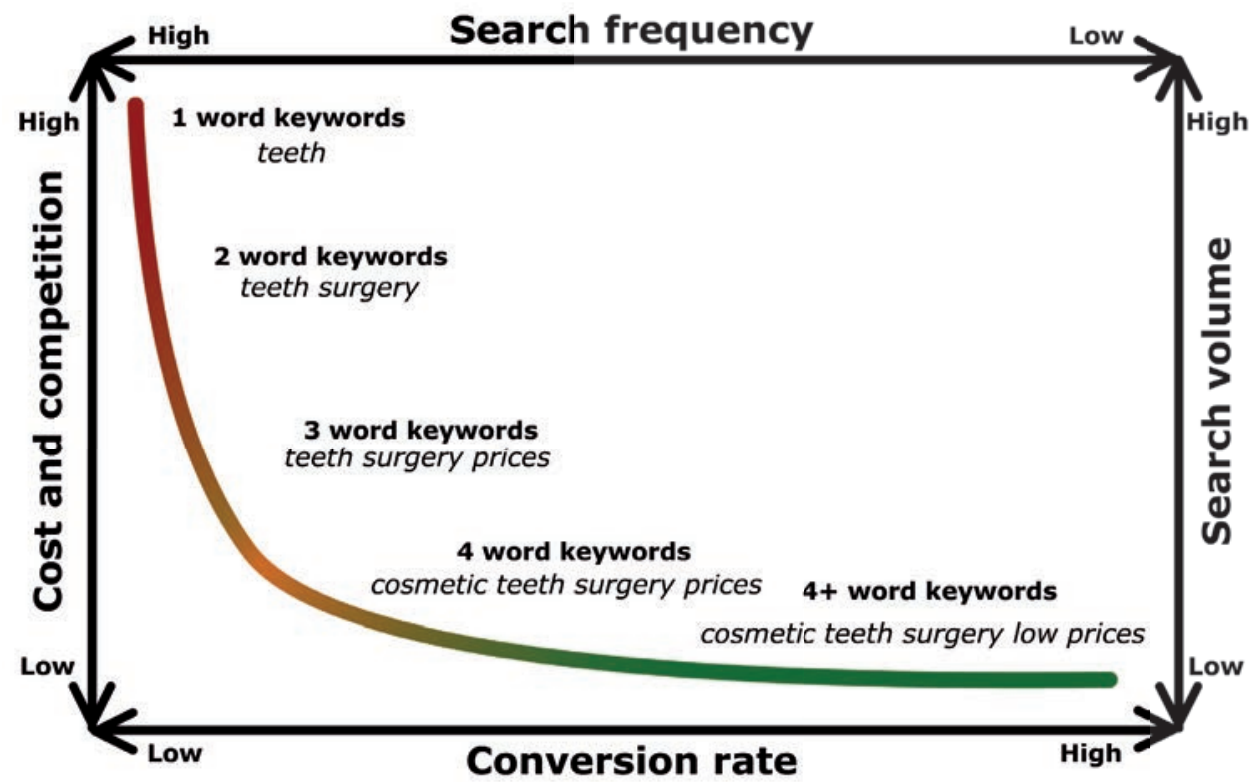

Figure 3: Efficiency of long tail keywords in web content marketing.

Considering that more than 400 suggested keywords are two- and threeword keywords, they need to be further looked up and extended to four or more words (not part of this study). This can be achieved by using various other open tools; see 3.1.2 and 3.1.3 below.

A third important factor into determining which keywords to be used in the term base is that of cost effectiveness for the potential client. For instance, tooth/teeth whitening procedures (using peroxide) can require lengthy periods, depending on the procedure used, and thus the beneficiary of the translation and localization can ask to remove such keywords. Probably this is why for the term dental tourism, a somewhat similar keyword, tooth/teeth bleaching, is listed only once. Seemingly, the newest whitening procedure can be effective in less than 30 minutes of treatment, during a single visit to a dentist professional. This is why it is important to check the term base against the beneficiary of the translation/localization service. Furthermore, the translator/localizer can suggest terms that are rather specific to the target market, that is, the UK in this case, such as walk in dentist, weekend dentist, dentist open on Saturday, dentist open on Sunday, dental spa, dentures in a day. 
Romanian dentist clinics may decide to implement such working strategies to come forward to the requirement of potential patients.

For marketing purposes, one can also use apparently inefficient keywords such as affordable dental implant hungary. The TT, as an instrumental translation process, can include phrases or subtitles such as Romania as an affordable alternative to dental implant in Hungary, with alternative as a key element in rendering the desired message, yet using a keyword very often searched for by UK search engine users.

For quick handling and quick curating Keyword Planner offers the possibility to save the suggested list as an excel file or directly to the user's Google Drive [10] account which can be used freely for curating and generating graphical data. The possible list of keywords can also be built by adding them to an advertising plan.

Also, such a list can be established by looking at the top websites that rank high in SERPS for various dental tourism suggested keywords. When analyzing the websites of the competitors, it is important to distinguish between the dental industry related keywords (dental tourism, dental school, dental jobs, etc.) and keywords that may be used by potential clients (dental implant costs, dental implants abroad, etc.).

Considering, for instance, dental implant costs abroad in google.co.uk and changing the IP (Internet protocol) address of the computer to a UK based IP (I used a free on-line IP changer [11] and accessed google.co.uk), relevant competitor web pages are displayed. Google.co.uk displays the first ten websites as if seen by a UK search engine user. Only the non-paid (organic) results should be considered (Table 2, accessed on the $28^{\text {th }}$ of August 2015).

All the URLs in Table 2 can be used for benchmarking and added as an option in Google AdWords Keyword Planner to retrieve keyword suggestions that are linked to these particular web pages. As an alternative, another free useful tool from internetmarketingninjas.com [12] can be used. It can compare up to five web pages and it shows useful information such as density of one-, two-, and three-word keywords.

Moving back to the suggestions provided by Keyword Planner, the list is organized, by default, in groups. However, to remove duplicates, keywords can be sorted by keywords. For example, preference should be given to the more specific keywords (long-tail keywords). Dental implants cost should be listed over dental implant.

Considering that two- and three-word keywords are inefficient and are not cost-effective, additional tools can be employed for turning them into lengthier keywords of four or more. 
1. Affordable Dental Tourism | Patients Beyond Borders www. patientsbeyondborders.com/procedure/dentistry - În cache - Pagini similare Sep 30, $2014 \ldots$... Find the most trusted low cost dental care with Patients Beyond ... The way to achieve those goals is often an implant, a crown, some ... Business travelers whose work takes them overseas may arrange for dental care while on ...

2. Dental Implants Abroad Cost $£ 400$ in Budapest - Kreativ Dental www.kreativdentalclinic.co.uk/dentist_abroad_hungary.php - În cache - Pagini similare Kreativ Dental offers dental implants abroad at a Cost of $£ 400$ these cheap teeth implantscome with a lifetime guarantee at our clinc in Budapest, Hungary.

3. Dental Implant: Affordable Treatment at Clinics Abroad - Medigo https://www.medigo.com/en/dentistry/dental-implant - În cache - Pagini similare

Evaluare: 4,4 - 102 voturi

May 9, 2015 ... MEDIGO lists clinics around the world offering Dental Implant procedures ... well connected with entire Europe by numerous low cost airlines.

4. Dental treatment abroad - Live Well - NHS Choices

www.nhs.uk/Livewell/Treatmentabroad/Pages/Dentistryabroad.aspx - În cache -Pagini similare

If you're considering dental treatment abroad, do your research and be aware of the ... For example, more than 50 different systems can be used for dental implants. ... by a qualified dentist before being given a treatment plan and cost estimate.

5. Dentalwise - Smart Holidays Dentistry | Dentistry Abroad Clinics

www. dentalwise.co.uk/ - În cache - Pagini similare

DentalWise is dentistry abroad and implant center where all your dental ... favourable rates on dental work - and dental implants abroad could cost you as little ...

6. Dental Implants Hungary | Cosmetic Dentistry Abroad | Affordable ..

kreativdentalclinic.eu/ - În cache - Pagini similare

Dental Implants, Crowns, Bridges, Dentures. Quality Dental Treatment At Affordable Prices in Budapest, Hungary.

7. Dentistry \& Dental Implants Abroad | Treatment Abroad

www.treatmentabroad.com/cosmetic-dentistry-abroad - În cache - Pagini similare

Visit the Treatment Abroad website for guides to dental treatment and cosmetic dentistryabroad including costs and quotes for treatment overseas.

8. Cheap dental implants abroad - $390 £$ each. Lifetime guarantee ...

www. affordabledentistry.co.uk/cheap-dental-implants-abroad/ - În cache - Pagini similare Cheap dental implants abroad at $390 £$ each. Implants and teeth same day. Cheapporcelain and zirconium crowns from $190 £$ each. Dental implants with ...

9. Dental Implants Abroad. Best Dental Implants Clinic in Bulgaria / Sofia. dental.implants.bg/?visit=implants_abroad - În cache - Pagini similare

How much do dental implants costs? Check our best prices for dental implants abroad.

10. Top 10 questions about receiving dental implants abroad - Dental ... www.dentaldepartures.com/.../top-10-questions-about-receiving-dental-implants-abroad/ În cache - Pagini similare

Feb 6, 2015... A dental implant is an artificial tooth root made of titanium that is ... At a specialty clinic abroad, the cost of an implant can be as little at $\$ 1000$.

Table 2: Top ten results for dental implants cost abroad, on google.co.uk (original text formatting is kept). 


\subsubsection{Google Search Engine Results Page (SERP)}

One such tool is the Google search engine results page (SERP) itself, by entering each of the relevant two- or three-word keywords into the search field. Most Google users are already familiar with these suggestions. These suggestions show up and update as you type.

\begin{tabular}{|l|l|} 
Google & dental implants ab \\
\hline & $\begin{array}{l}\text { dental implants abroad } \\
\text { dental implants aberdeen } \\
\text { dental implants aberdeen cost } \\
\text { dental implants abergavenny }\end{array}$ \\
\hline
\end{tabular}

Figure 4: Google suggestions within the search engine.

\subsubsection{SERP Long-tail Keywords}

At the end of each SERP, Google provides related long-tail keywords.

$\begin{array}{ll}\begin{array}{l}\text { Searches related to dental implants abroad } \\ \text { best countries for dental implants }\end{array} & \text { save on dental care } \\ \begin{array}{ll}\text { dental implants abroad reviews } & \text { dental implants abroad turkey } \\ \text { dental implants cost } & \text { best dental implants abroad } \\ \text { dental implants abroad forum } & \text { dental implants abroad cost }\end{array}\end{array}$

Figure 5: Google suggestions at the end of the SERP.

\subsection{4 ubersuggest.com}

A useful tool that automates this task substantially is ubersuggest.com. 


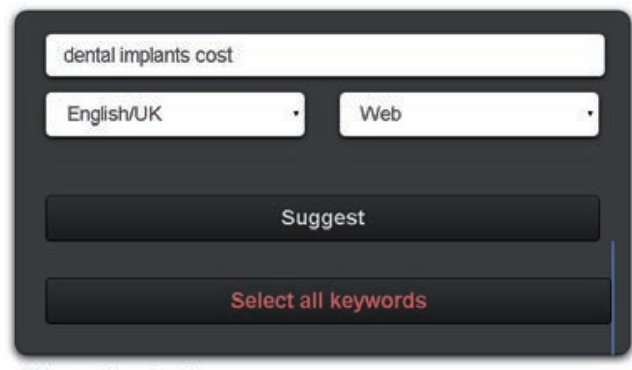

875 suggestions found.

original - $\underline{\mathrm{a}} \underline{\mathrm{b}} \underline{\mathrm{c}} \underline{\mathrm{d}} \underline{\mathrm{e}} \mathrm{f} \mathrm{g} \underline{\mathrm{h}} \underline{\mathrm{i}} \mathrm{i} \underline{\mathrm{k}} \underline{\mathrm{l}} \mathrm{m} \underline{\mathrm{n}} \underline{\mathrm{o}} \underline{\mathrm{p}}$

g $\underline{\mathrm{r}} \underline{\mathrm{s}} \underline{\mathrm{t}} \underline{\mathrm{u}} \underline{\mathrm{v}} \underline{\mathrm{w}} \underline{\mathrm{x}} \underline{\mathrm{y}} \underline{\underline{z}} \underline{0} \underline{1} \underline{2} \underline{3} \underline{4} \underline{5} \underline{6} \underline{7} \underline{8} \underline{9}$

idental implants cost

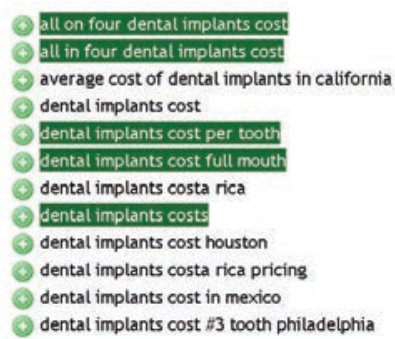

Figure 6: Ubersuggest suggestions (partial list).

For instance, if dental implants cost is looked up there are many suggestions that are linked to a certain geographical area, from various parts of the world that seem unlikely to be looked up from the UK, for instance dental implants cost full mouth virginia or dental implants cost columbus ohio. On the other hand, there are also quite many useful suggestions such as dental implants cost per tooth, dental implants cost full mouth.

\subsubsection{Google Trends}

Relevance and number of search queries and their trend can be checked and compared by using another free tool, Google Trends (set to https://www.google.co.uk/trends/?hl=en). For instance, it is important to know which the predominant keyword used should be if we compare dental implants costs vs. dental implant prices. 


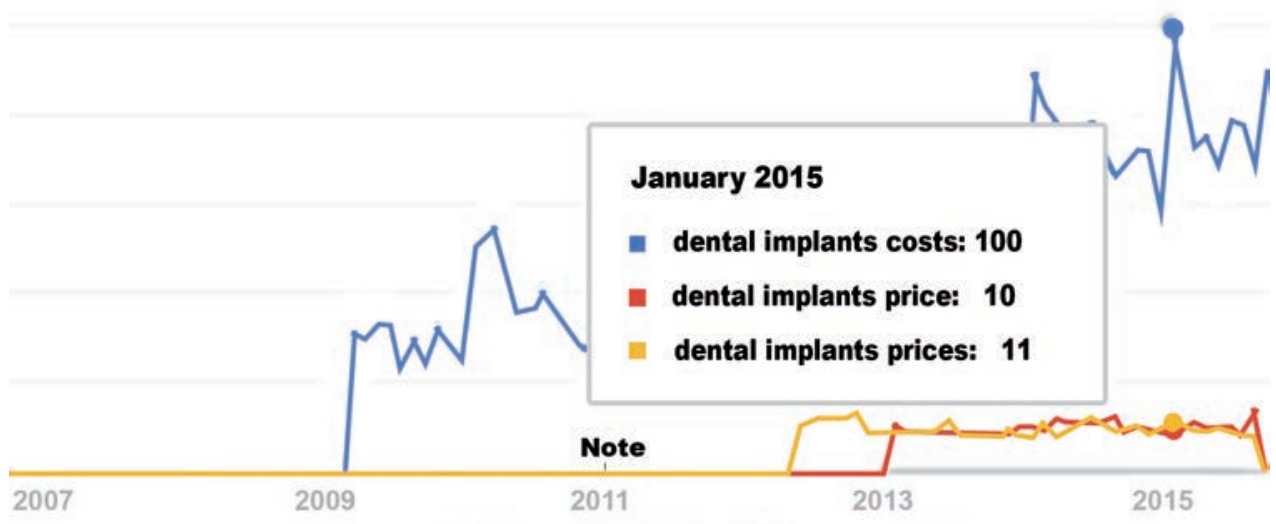

Figure 7: Comparison of various keywords as used by search engine users from the UK.

As it can be noticed, dental implants cost has been used ever since 2009, while the other two alternatives only later. Once all three alternatives are used, the diagram shows a clear predominance of the initial keywords. This demonstrates that some synonymous expressions should be used over their alternatives. Google Trends, as its name suggests, can also offer information on related concepts or on similar expressions. In this case, it displays the top rising keywords, reconfirming or adding to the information provided in Google Keyword Planner: Dental implant - Medical Treatment, cost of implants, dental implants uk, nhs dental implants, teeth implants, teeth implants cost, dental implant, dental implant cost, tooth implants cost, tooth implants, dentures cost.

\subsection{Keywords as Translation Units}

To a great extent, keywords found in the pre-editing stage can be considered translation units. However, the length of the translation units from the ST and the TT will not necessarily be similar. One- and two-word keywords in the ST can become long-tail keywords in the TT; moreover a two-word keyword in the ST can be efficient and cost effective since the competition in a marginal culture such as Romanian may be less fierce. On the other hand, the UK market would require long-tail keywords for successful content marketing. One impediment against associating keywords to translation units is that keywords are often unnatural sounding. Also, the on-line marketing industry considers many of the linking words that make a language sound natural as 
"stop words". A list of such words can be found at:

http://wwww.internetmarketingninjas.com/seo-tools/seo-compare/lib/stop_words.txt

\subsection{Usage of the SEO Researched Term Base}

Usage of keywords in the TT should be natural, that is, in a normal way of writing. The Google indexing algorithm has evolved to such a level that it can determine if a text is overfilled with certain keywords. If the keywords are not rendered in a natural way and are meant for indexing purposes (an improper technique to fool the search engine), the web page and website is penalized. For instance, dental implant costs romania should be used in the TT as ... dental implant costs in Romania....

In order to cover as much of the potential market as possible while complying with the requirements of search engines, the translator should use predominantly the keywords that are most often used. However, synonymous expressions, related keywords, and even antonymic, yet relevant ones (see example with the keywords containing the word hungary), singular and plural forms should also be used. However, considering that the ST, in this case Romanian, may be very different from the TT, as the suggested approach is that of instrumental translation, rendering the text in a natural manner is of paramount importance. As the Google documentation guide suggests [13] the text should be written for the reader and not for the search engines. Due to the same instrumental translation approach TT text length will vary from that of the ST. Also, in terms there is a good policy to check the text length particular for a certain web market segment in the target culture.

\subsection{Rage Against the Machine in Translation}

The term base built using the open tools described above can be used in translation memories (TM) for automating translations. However, in the case of web content marketing, using and overusing the same keywords (even more so if we consider the long-tail keywords) can result in penalization from search engines. Using Wikipedia or other free community-driven websites for building a term base for a specific field of human activity can also lead to nonvoluntary plagiarism. This can occur from overusing such sources that make up a translation memory. In order to be indexed in search engines, it is important that the content be new and original in the target language.

Also, in theory, articles may require "rewriting" by using new predominant keywords, or adding alternatives (see Google Trends); however, the life cycle of articles is usually shorter than the life cycle of certain keywords (dental implants cost vs. dental implants prices). As a counterexample, keywords that contain a time stamp have a reduced life cycle and so do the articles that 
contain them; consider dental implant costs 2015. While it reflects updated information, its life cycle is limited to 2015. Search engines value unique, updated, and valuable content, so there is not much room for automatisms.

\section{Conclusions}

This type of approach to the pre-editing translation process is beneficial as it provides reliable statistical data, and can be applied successfully especially to web content marketing. The tools needed to achieve such translations are free to use and therefore can be used by anyone, from freelancers and small companies to multinationals. For determining the most lucrative set of keywords, moving back and forth with each of these tools may be required.

By employing a marketing approach to instrumental translation, the beneficiary of the text gains a competitive edge over its competitors; hence, the outcome is a value added translation. Pym (cited in Dimitriu 2002: 98), suggests moving from a purely linguistic perspective to a sociological and economic one, as in the case of websites, more often than not, the driving engine is generating sales. Building texts based on the language expressions used by the potential clients opens up more efficient communication channels. Also, this approach implies a rather copy-writing-like process, namely moving further away from the ST. The main benefit is that the TT is far less under the influence of the ST which makes integration into the target culture much smoother.

Regarding the applicability of this method, for the purpose of this paper we considered Romanian as the source language/culture and British English as the target language/culture. However, this method is reusable and reproducible with any language/culture pairs and can be applied to any industry by using the same open tools or similar ones.

\section{References}

Dimitriu, R. (2002) Theories and Practice of Translation. Iași: Institutul European.

Dimitriu, R. (2009) Key words and concepts in E. A. Nida's approach to translation and their further development in Translation Studies. In Dimitriu, R. and Shlesinger, M. (eds.) Translators and Their Reader, Brussells: Les Éditions du Hazard, 23-41.

Lakó, C. (2009) Translating for the Web - The Keyword Oriented Translation Process. In The Proceedings of the European Integration - Between Tradition and Modernity Congress (3), Târgu-Mureş: Editura Universităţii “Petru Maior", 761-767.

Nord, C. (1997) Translating as a Purposeful Activity. Functionalist Approaches Explained. Manchester, UK: St. Jerome Publishing. 
Nord, C. (2005) Text Analysis in Translation: Theory, Methodology, and Didactic Application of a Model for Translation-Oriented Text Analysis, Amsterdam: Rodopi.

Schäler, R. (2002) Reverse Localization. The International Journal of Localisation, Vol.6, Issue 1, Localisation Research Centre, CSIS Dept, University of Limerick, Limerick Ireland, 39-48.

\section{Internet sources:}

[1]https://www.marketingsherpa.com/data/public/reports/special-reports/SR-A-TacticalApproach-to-Content-Marketing.pdf

[2] https://adwords.google.com/KeywordPlanner

[3] http://www.bing.com/toolbox/keywords

[4] https://www.google.com/trends/

[5] http://www.merriam-webster.com/dictionary/site]

[6] https://dexonline.ro/ definitie/sit

[7] http://ds6.net/wp-content/uploads/2014/05/LongtailEbook.pdf

[8] http://neilpatel.com/2015/05/07/a-step-by-step-guide-to-integrating-long-tail-keywordswithin-blog-posts/

[9] http://www.business2community.com/seo/secrets-using-long-tail-keywords01154759\#bZAmD3APR239xmfl.97

[10] https://drive.google.com

[11] http://www.onlineipchanger.com/

[12] https://uww.internetmarketingninjas.com/seo-tools/seo-compare/

[13] http://static.googleusercontent.com/media/www.google.com/ro//webmasters/docs/searchengine -optimization-starter-guide.pdf 
